\title{
Decreased hypertrophic differentiation accompanies enhanced matrix formation in co-cultures of outer meniscus cells with bone marrow mesenchymal stromal cells
}

\author{
David JJ Saliken, Aillette Mulet-Sierra, Nadr M Jomha and Adetola B Adesida*
}

\begin{abstract}
Introduction: The main objective of this study was to determine whether meniscus cells from the outer (MCO) and inner $(\mathrm{MCl})$ regions of the meniscus interact similarly to or differently with mesenchymal stromal stem cells (MSCs). Previous study had shown that co-culture of meniscus cells with bone marrow-derived MSCs result in enhanced matrix formation relative to mono-cultures of meniscus cells and MSCs. However, the study did not examine if cells from the different regions of the meniscus interacted similarly to or differently with MSCs.
\end{abstract}

Methods: Human menisci were harvested from four patients undergoing total knee replacements. Tissue from the outer and inner regions represented pieces taken from one third and two thirds of the radial distance of the meniscus, respectively. Meniscus cells were released from the menisci after collagenase treatment. Bone marrow MSCs were obtained from the iliac crest of two patients after plastic adherence and in vitro culture until passage 2. Primary meniscus cells from the outer (MCO) or inner (MCl) regions of the meniscus were co-cultured with MSCs in three-dimensional (3D) pellet cultures at 1:3 ratio, respectively, for 3 weeks in the presence of serum-free chondrogenic medium containing TGF- $\beta$ 1. Mono-cultures of MCO, MCI and MSCs served as experimental control groups. The tissue formed after 3 weeks was assessed biochemically, histochemically and by quantitative RT-PCR.

Results: Co-culture of inner (MCl) or outer (MCO) meniscus cells with MSCs resulted in neo-tissue with increased (up to 2.2-fold) proteoglycan (GAG) matrix content relative to tissues formed from mono-cultures of $\mathrm{MSCs}, \mathrm{MCl}$ and MCO. Co-cultures of $\mathrm{MCl}$ or MCO with MSCs produced the same amount of matrix in the tissue formed. However, the expression level of aggrecan was highest in mono-cultures of MSCs but similar in the other four groups. The DNA content of the tissues from co-cultured cells was not statistically different from tissues formed from monocultures of MSCs, MCI and MCO. The expression of collagen I (COLIA2) mRNA increased in co-cultured cells relative to mono-cultures of MCO and MCI but not compared to MSC mono-cultures. Collagen II (COL2A1) mRNA expression increased significantly in co-cultures of both $\mathrm{MCO}$ and $\mathrm{MCI}$ with MSCs compared to their own controls (mono-cultures of MCO and $\mathrm{MCI}$ respectively) but only the co-cultures of MCO:MSCs were significantly increased compared to MSC control mono-cultures. Increased collagen II protein expression was visible by collagen II immuno-histochemistry. The mRNA expression level of Sox9 was similar in all pellet cultures. The expression of collagen $\times($ COL1OA1) mRNA was 2-fold higher in co-cultures of MCl:MSCs relative to co-cultures of MCO:MSCs. Additionally, other hypertrophic genes, MMP-13 and Indian Hedgehog $(I H h)$, were highly expressed by 4-fold and 18-fold, respectively, in co-cultures of MCl:MSCs relative to co-cultures of MCO:MSCs.

Conclusions: Co-culture of primary $\mathrm{MCl}$ or MCO with MSCs resulted in enhanced matrix formation. $\mathrm{MCI}$ and $\mathrm{MCO}$ increased matrix formation similarly after co-culture with MSCs. However, MCO was more potent than MCI in

\footnotetext{
* Correspondence: adesida@ualberta.ca Laboratory of Stem Cell Biology and Orthopaedic Tissue Engineering, Department of Surgery, Division of Orthopaedic Surgery, University of Alberta, Edmonton, AB, T6G 2R3, Canada
} 


\section{Introduction}

The meniscus of the knee joint serves a variety of critical functions that include shock absorption, cartilage protection, and joint stability [1-3]. The capacity to perform these functions is by virtue of its extracellular matrix (ECM) composition and assembly, which is accomplished entirely by meniscus fibrochondrocytes $[4,5]$. The ECM consists predominantly of type I collagen throughout, type II collagen in the inner meniscus, and proteoglycans, of which aggrecan is predominant [6-8]. Unfortunately, the reparative capacity of the meniscus is hindered by limited vascularization [9]. In human meniscus, the capillary plexus supplies only the outer one third [10] whereas the inner two thirds are avascular; if left untreated, defects in this portion do not heal and may lead to further joint degeneration $[11,12]$. Current treatment options include partial and total meniscectomies, depending on the extent of meniscal injury [13]. However, these procedures are major risk factors for the early development of osteoarthritis (OA) [13-16]. Cell-based regenerative medicine and tissue engineering have been advocated options to produce functional substitutes to aid repair or replace damaged tissue [17-28]. However, current protocols suffer from several drawbacks that include insufficient numbers of differentiated meniscus cells and loss of ECM-forming phenotype of in vitro-propagated meniscus cells. Therefore, alternative cell sources or cell-based strategies are of interest in meniscus tissue engineering.

Adult-derived mesenchymal stromal stem cells (MSCs) are of particular interest in meniscus tissue engineering because of their capacity to undergo differentiation into a variety of mesenchymal lineages, including cartilage and bone $[17,29,30]$. Additionally, MSCs secrete soluble trophic factors that are capable of promoting cell proliferation and differentiation and suppressing local immune system through both autocrine and paracrine mechanisms [31-35]. However, specific factors known to induce MSCs toward the meniscus cell phenotype are unknown. Co-culture of MSCs with primary meniscus cells is a stratagem that both provides inductive factors and mitigates the need for meniscus cell expansion and associated dedifferentiation of meniscus cells during in vitro culture expansion [32,34-38]. Recent work in our laboratory demonstrated that supplementation of human primary meniscus cells with human bone marrow MSCs results in increased meniscus matrix-forming phenotype [39]. Similar work by Cui and colleagues [40] additionally demonstrated that co-cultures of primary human meniscus cells with bone marrow MSCs result in suppression of hypertrophic differentiation of bone marrow MSCs. However, both studies used meniscus cells taken from the whole meniscus and it is not clear whether the cells from the outer and inner menisci will interact similarly or distinctly with bone marrow MSCs. Previous studies have shown that the meniscus cells from the outer and inner regions of the meniscus have distinct ECM gene profiles as well as different multilineage differentiation characteristics [41-43]. Moreover, inner meniscus cells display a more chondrogenic phenotype relative to outer meniscus cells on the basis of inherently higher collagen II and aggrecan content $[42,43]$. Furthermore, outer meniscus cells displayed a more chondrogenic response to hypoxic stimuli by enhanced expression of chondrogenic genes, collagen II and Sry-related HMG box 9 (sox9), than cells isolated from the inner and avascular regions of the meniscus [44]. In this study, we explored the concepts that (a) cells of outer and inner menisci have the capacity to enhance matrix formation of meniscus cells after co-culture with MSCs and (b) cells from the outer and selfhealing regions of the meniscus may serve as a clinical source of cells in co-culture tissue engineering strategies with MSCs to recapitulate the functional matrix-forming phenotype of the inner meniscus, which has a limited reparative capacity.

\section{Materials and methods}

\section{Collection of bone marrow specimens and culture of} bone marrow stem cells

Bone marrow aspirates were obtained from surgically discarded material after approval and a waiver of informed consent of the local ethical committee of the University of Alberta (Edmonton, AB, Canada) during routine orthopedic procedures from the iliac crest of two female donors (ages of 23 and 59 years). The number of nucleated cells in the aspirates was determined by crystal violet nuclei staining and counting on a hemocytometer. Thereafter, 15 million nucleated cells per $150-\mathrm{cm}^{2}$ tissue culture flask were seeded. Culture medium was alpha minimum essential medium supplemented with $10 \%$ heat-inactivated fetal bovine serum, $1 \mathrm{mM}$ sodium pyruvate, $100 \mathrm{mM}$ HEPES buffer, $1 \mathrm{mM}$ sodium pyruvate, $100 \mathrm{U} / \mathrm{mL}$ penicillin, $100 \mu \mathrm{g} / \mathrm{mL}$ streptomycin, and $0.29 \mathrm{mg} / \mathrm{mL}$ L-glutamine (all from Invitrogen, Mississauga, ON, Canada) and $5 \mathrm{ng} / \mathrm{mL}$ of basic fibroblast 
growth factor 2 (FGF-2) (Humanzyme-Medicorp Inc., Montreal, QC, Canada). Nucleated cells were allowed to adhere and grow for 7 days before the first media change under normal oxygen tension $\left(21 \% \mathrm{O}_{2}\right.$ and $95 \%$ air) at $37^{\circ} \mathrm{C}$ in a humidified incubator with $5 \% \mathrm{CO}_{2}$. Thereafter, media change was implemented twice per week until $70 \%$ to $80 \%$ cell confluence was attained. These adherent bone marrow MSCs were detached by using trypsin-ethylenediaminetetraacetic acid (trypsinEDTA) $(0.05 \% \mathrm{wt} / \mathrm{vol})$ and expanded until passage 2 prior to experimental use. We included FGF-2 throughout MSC cultivation as it maintains human MSCs in an immature state for in vitro expansion [45].

\section{Isolation of human meniscus cells}

Menisci were obtained from surgically discarded material after approval and a waiver of informed consent of the local ethical committee of the University of Alberta. Both lateral and medial menisci were harvested from the knee joint of four female donors (age of 55 to 71 years and mean age of $62 \pm 6.8$ years) undergoing total knee arthroplasty. Tissue from the outer and inner regions represented pieces taken from one third and two thirds of the radial distance, respectively. Meniscus cells were released via treatment with type II collagenase $(0.2 \% \mathrm{wt} / \mathrm{vol}$; Worthington, Lakewood, NJ, USA) after 16 -hour digestion of tissue at $37^{\circ} \mathrm{C}$ in a standard medium-high glucose Dulbecco's modified Eagle's medium containing $4.5 \mathrm{mg} / \mathrm{mL}$ D-Glucose (DMEM-HG), 0.1 $\mathrm{mM}$ non-essential amino acids, $1 \mathrm{mM}$ sodium pyruvate, $100 \mathrm{mM}$ HEPES buffer, $1 \mathrm{mM}$ sodium pyruvate, $100 \mathrm{U} /$ $\mathrm{mL}$ penicillin, $100 \mu \mathrm{g} / \mathrm{mL}$ streptomycin, and $0.29 \mathrm{mg} /$ $\mathrm{mL}$ L-glutamine (all from Invitrogen) supplemented with 10\% fetal bovine serum (Invitrogen). Meniscus cells from the outer meniscus region were labeled as MCO, and those from the inner portion of the meniscus were designated as MCI. The cell suspension obtained after digestion was passed through a $70-\mu \mathrm{m}$ nylon-mesh filter. Isolated cells were plated at $104 \mathrm{cells} / \mathrm{cm} 2$ and cultured in standard medium for 24 hours under normal oxygen tension $\left(21 \% \mathrm{O} 2\right.$ and $95 \%$ air) at $37^{\circ} \mathrm{C}$ in a humidified incubator with $5 \% \mathrm{CO} 2$ before experimental use. Nonadherent cells were aspirated off while adherent cells were detached with trypsin-EDTA $(0.05 \% \mathrm{wt} / \mathrm{vol})$ (Invitrogen).

\section{Chondrogenic differentiation}

Mono-culture in pellets of MSCs, $\mathrm{MCO}$, and $\mathrm{MCI}$ were formed in $250 \mu \mathrm{L}$ of serum-free chondrogenic culture medium consisting of standard medium supplemented with $0.1 \mathrm{mM}$ ascorbic acid 2-phosphate, $10^{-5} \mathrm{M}$ dexamethasone, $1 x$ ITS +1 premix (Sigma-Aldrich, Oakville, $\mathrm{ON}$, Canada), and $10 \mathrm{ng} / \mathrm{mL}$ transforming growth factor-beta 1 (TGF- $\beta 1$ ) (Humanzyme-Medicorp Inc.) as described previously [35]. A total of $2.5 \times 10^{5}$ cells were spun in $1.5 \mathrm{~mL}$ of sterile conical polypropylene microfuge tubes (Enzymax LLC, Lexington, KY, USA) at 1,500 revolutions per minute for 3 minutes to form spherical cell pellets. Co-cultures in pellet form consisting of $\mathrm{MCO} / \mathrm{MSCs}$ or $\mathrm{MCI} / \mathrm{MSCs}$ were formulated by mixing the two cell types at a 1:3 ratio, respectively. Preliminary studies with a variety of ratios had shown a ratio of $1: 3$ to reproducibly result in enhanced matrix formation, but identification of the optimal cell-cell ratio remains to be determined [46]. After 3 weeks of culture with media changes three times per week, pellets were processed biochemically for glycosaminoglycan (GAG) and DNA contents, histologically, and immuno-histochemically and by quantitative reverse transcription-polymerase chain reaction for gene expression analysis. For each experiment (four in total), there were two experimental groups (co-culture of $\mathrm{MCO} / \mathrm{MSCs}$ and co-culture of $\mathrm{MCI} / \mathrm{MSCs}$ ) and three control groups (mono-culture of MSCs, mono-culture of MCO, and mono-culture of $\mathrm{MCI})$. At least two or three replicate pellets per control or experimental group were assessed for each experiment.

\section{Biochemical analysis}

All in vitro cultivated pellets were rinsed in phosphatebuffered saline (Invitrogen) and digested in proteinase $\mathrm{K}$ $(1 \mathrm{mg} / \mathrm{mL}$ in $50 \mathrm{mM}$ Tris with $1 \mathrm{mM}$ EDTA, $1 \mathrm{mM}$ iodoacetamide, and $10 \mathrm{mg} / \mathrm{mL}$ pepstatin $\mathrm{A}$; all from Sigma-Aldrich) for 16 hours at $56^{\circ} \mathrm{C}$. The sulphated GAG content was measured by 1,9 dimethylmethylene blue binding (Sigma-Aldrich) by using chondroitin sulphate (Sigma-Aldrich) as standard [47]. The DNA content was determined by using the CyQuant cell proliferation assay kit (Invitrogen) with supplied bacteriophage $\lambda$ DNA as standard. Based on experimental GAG values of mono-culture of MSC, MCO, or MCI pellets, the expected GAG values were calculated as a linear function of the proportion (percentage) of MSCs and MCO or MSCs and MCI by using the following equations [35,39]:

$$
\begin{aligned}
& \mathrm{GAG}_{\text {expected }}=\left[\left(\mathrm{GAG}_{100 \% \mathrm{MSCs}} \times \% \mathrm{MSCs}\right)+\left(\mathrm{GAG}_{100 \% \mathrm{MCI}} \times \% \mathrm{MCI}\right)\right] \\
& \mathrm{GAG}_{\text {expected }}=\left[\left(\mathrm{GAG}_{100 \% \mathrm{MSCs}} \times \% \mathrm{MSCs}\right)+\left(\mathrm{GAG}_{100 \% \mathrm{MCO}} \times \% \mathrm{MCO}\right)\right] .
\end{aligned}
$$

The interaction index or measure of chondro-induction was then calculated as the ratio of measured GAG (that is, $\mathrm{GAG}_{\text {measured }}$ ) in co-cultured pellets to expected GAG (that is, $\mathrm{GAG}_{\text {expected}}$ ). If the value of the ratio is greater than 1, then chondro-induction, an enhanced chondrogenic matrix formation, is considered to have taken place $[35,39]$. 


\section{Histology and immuno-histochemistry}

Tissues generated from the pellet cultures were fixed in $4 \%$ phosphate-buffered formalin, processed into paraffin wax, sectioned at $5 \mu \mathrm{m}$, and stained with $1 \%$ Alcian blue and counterstained with $1 \%$ neutral red stain to reveal sulphated proteoglycan (GAG) matrix depositions. Other sections were probed with antibodies raised against collagen types I and II. Sections were digested with trypsin and then incubated with antibodies against collagen I (MAB3391) from Millipore (Temecula, CA, USA) or collagen II (II-II6B3) from the Developmental Studies Hybridoma Bank at the University of Iowa (Iowa City, IA, USA). Immuno-localized antigens were visualized with goat anti-mouse IgG biotinylated secondary antibody (Dako Canada Inc., Mississauga, ON, Canada) and a streptavidin-horseradish peroxidase labeling kit with 3,3'-diaminobenzidine (Dako Canada Inc.). Images were captured by using an Omano OM159T biological trinocular microscope (Microscope Store, Roanoke, VA, USA) fitted with an Optixcam summit series 5MP digital camera and Optixcam software and assembled in Adobe Photoshop (Adobe Systems Inc., Mountain View, CA, USA).

\section{Gene expression analysis}

Total RNA was extracted from pellets by using TriReagent (Sigma-Aldrich) after grinding with Molecular Grinding Resin (Geno Technology Inc., St. Louis, MO, USA) in combination with the use of an Aurum Total RNA Fatty and Fibrous Tissue Kit (Bio-Rad, Mississauga, ON, Canada) and after removal of contaminating genomic DNA from the pellets by DNase treatment. To minimize changes in gene expression during cell pellet harvest, cell pellets were immediately (less than $1 \mathrm{~min}$ ute) transferred into Tri-Reagent. Total RNA (100 ng) in a $40-\mu \mathrm{L}$ reaction was reverse-transcribed to cDNA by using GoScript reverse transcriptase primed with oligo $(\mathrm{dT})_{15}$ primer (Fisher Scientific, Whitby, ON, Canada). Quantitative real-time polymerase chain reaction was performed in DNA Engine Opticon II Continuous Fluorescence Detection System (Bio-Rad) by using hot start Taq and SYBR Green detection (Eurogentec North America Inc., San Diego, CA, USA). Primer sequences for collagen I (COL1A2), collagen II (COL2A1), collagen $\times(C O L 10 A 1)$, aggrecan, versican, SOX9, and $\beta$-actin (Table 1) were taken from previously published work or were custom designed by using Primer Express software (Applied Biosystems, Foster City, CA, USA) [44,48,49]. All primers were obtained from Invitrogen. Gene (mRNA) expression levels for each primer set were normalized to the expression level of $\beta$-actin by the $2_{-}{ }^{\Delta \mathrm{ct}}$ method [50].

\section{Statistical analysis}

Data are presented as mean \pm standard error of mean of measurements. All statistical analyses were performed by using SPSS version 18 (PASW Statistics 18; SPSS Inc., Chicago, IL, USA) unless stated otherwise. Experimental and control groups were compared with oneway analysis of variance with Tukey's multiple comparison post hoc tests. Statistical differences between chondro-induction indices of MCO and MSC experimental groups and/or MCI and MSC experimental groups were assessed by paired two-tailed Student $t$ test distribution. All statistical differences were considered to be significant with a $P$ value of less than 0.05 .

Table 1 Primer sequences used in quantitative real-time polymerase chain reaction

\begin{tabular}{|c|c|c|c|}
\hline Gene & Primer & Direction & Reference or GenBank accession number \\
\hline Beta-actin & $\begin{array}{l}\text { 5'-AAGCCACCCCACTTCTCTCTAA-3' } \\
\text { 5'-AATGCTATCACCTCCCCTGTGT-3' }\end{array}$ & $\begin{array}{l}\text { Forward } \\
\text { Reverse }\end{array}$ & {$[36]$} \\
\hline Aggrecan & $\begin{array}{l}\text { 5'-AGGGCGAGTGGAATGATGTT-3' } \\
\text { 5'-GGTGGCTGTGCCCTIIITAC-3' }\end{array}$ & $\begin{array}{l}\text { Forward } \\
\text { Reverse }\end{array}$ & [36] \\
\hline $\begin{array}{l}\text { Collagen I } \\
\text { (COL1A2) }\end{array}$ & $\begin{array}{l}\text { 5'-TTGCCCAAAGTTGTCCTCTTCT-3' } \\
\text { 5'-AGCTTCTGTGGAACCATGGAA-3' }\end{array}$ & $\begin{array}{l}\text { Forward } \\
\text { Reverse }\end{array}$ & [36] \\
\hline $\begin{array}{l}\text { Collagen II } \\
\text { (COL2A1) }\end{array}$ & $\begin{array}{l}\text { 5'-CTGCAAAATAAAATCTCGGTGTTCT-3' } \\
\text { 5'-GGGCATITGACTCACACCAGT-3' }\end{array}$ & $\begin{array}{l}\text { Forward } \\
\text { Reverse }\end{array}$ & [36] \\
\hline Collagen $\times($ COL10A1) & $\begin{array}{c}\text { 5'-CAAGGCACCATCTCCAGGAA-3' } \\
\text { 5'-AAAGGGTATTIGTGGCAGCATATT-3' }\end{array}$ & $\begin{array}{l}\text { Forward } \\
\text { Reverse }\end{array}$ & [35] \\
\hline $\mathrm{Hh}$ & $\begin{array}{l}\text { 5'-CCTTGTCAGCCGTGAGGCCG-3' } \\
\text { 5'-GCTGCCGGCTCCGTGTGATT-3' }\end{array}$ & $\begin{array}{l}\text { Forward } \\
\text { Reverse }\end{array}$ & NM_00218.3 \\
\hline MMP-13 & $\begin{array}{l}\text { 5'-TGGAAGGATGCCTIIIITCTC-3' } \\
\text { 5'-CACCCTCCCCAAGTATCAATAGG-3' }\end{array}$ & $\begin{array}{l}\text { Forward } \\
\text { Reverse }\end{array}$ & NM_002427 \\
\hline sox9 & $\begin{array}{l}\text { 5'-CाTGGTाTGTGTTCGTGTाTG-3' } \\
\text { 5'-AGAGAAAGAAAAAGGGAAAGGTAAGTाT-3' }\end{array}$ & $\begin{array}{c}\text { Forward } \\
\text { Reverse }\end{array}$ & [31] \\
\hline Versican & $\begin{array}{c}\text { 5'-TGGAATGATGTTCCCTGCAA-3' } \\
\text { 5'-AAGGTCTTGGCATTITCTACAACAG-3' }\end{array}$ & $\begin{array}{l}\text { Forward } \\
\text { Reverse }\end{array}$ & {$[35]$} \\
\hline
\end{tabular}

All primers were purchased from Invitrogen (Mississauga, ON, Canada). COL1A2, type II collagen $\alpha 2$ chain; COL2A1, type I collagen $\alpha 1$ chain; COL10A1, type $\times$ collagen $\alpha 1$ chain; IHh, Indian Hedgehog; MMP-13, matrix metalloproteinase 13; SOX9, Sry-related HMG box 9. 


\section{Results}

Enhanced synthesis of glycosaminoglycan matrix in cocultured pellets of meniscus cells and mesenchymal stromal cells

To characterize the ECM accumulated after pellet culture, the amount of GAG matrix production per cellular DNA content was quantified (Figure 1A). All pellets from co-cultured cells displayed a significantly higher $(P$ $<0.01$ ) GAG per DNA content (a measure of chondrogenic capacity) than pellets derived from mono-cultures of MSCs. However, the GAG per DNA content of cocultured pellets was not significantly $(P>0.05)$ different from that of pellets formulated from mono-cultures of MCI or MCO (Figure 1A), thus indicating that the enhanced capacities to synthesize the cartilaginous-type ECM of the MCO or MCI in co-culture with MSCs are similar.

To determine whether changes in the number of cells accounted for the difference or similarities in chondrogenic capacities of the co-cultured pellets relative to pellets from mono-cultures of MSCs, MCO, and MCI, we determined the DNA content since DNA content per cell is $11.6 \mathrm{pg}$ [51]. All pellets were not significantly $(P$ $>0.05$ ) in DNA content (Figure 1B).

To quantify the different enhanced capacity of the cocultured pellets and MSCs to produce GAG-type matrix, the chondrogenic index was calculated as the ratio of the experimental GAG value to the expected GAG value. Expected GAG value was determined as a linear function of the proportion of meniscus cells (that is, MCI or MCO) and MSCs in co-cultured pellets (Equations 1 and 2). Chondrogenic indices that exceeded 1 were considered to display chondro-induction, which is an enhancement in chondrogenic capacity. All co-cultured pellets had chondro-induction indices of above 1 . Chondro-induction indices ranged from 1.2 to 2.1 for $\mathrm{MCI} / \mathrm{MSC}$ co-cultures and from 1.4 to 2.2 for $\mathrm{MCO} /$ MSC co-cultures (Figure $1 \mathrm{C}$ ). However, there was no significant difference between the two groups.

Histological assessment of matrix deposition in co-culture of meniscus cells and mesenchymal stromal stem cells

Cells were cultured from four donor pairs; primary meniscus cells from the outer (MCO) or inner (MCI) region of the meniscus with bone marrow MSCs were cultured, in separate pellets (mono-cultured pellets) or after being mixed (co-cultured pellets), for 3 weeks in serum-free medium supplemented with chondrogenic factors (TGF- $\beta 1$, ascorbic acid, and dexamethasone). Representative data from co-cultured pairs of four donors are shown in Figure 2. All five groups were positive for proteoglycan staining by safranin O (Figure 1, 2) and Alcian blue (Figure 1,2) after chondrogenic stimulation (Figure 2). Relative to the mono-cultured pellets (Figure 2B1, B3, and 2B5), the Alcian blue staining intensity in co-cultured pellets (Figure 2B2 and 2B4) appeared to be more intense and homogenously distributed.

Immuno-histochemical assessment of all mono-cultured and co-cultured pellets was performed by using antibodies to types I and II collagen. All pellets stained positively (brown coloration) for types I and II collagen. Representative photomicrographs for collagen I are shown in Figures 1, 2 and for collagen II in Figures 1, 2. Collagen I stain was evenly distributed in all cell pellets (Figures 1, 2). In contrast, with the exception of monoculture pellets of MSCs (Figure 2D1), collagen II staining was not homogenously distributed over entire pellets (Figure 2). Mono-cultured pellets of MCI (Figure 2D3) were labeled predominantly with collagen II in the central portion of the pellets, whereas pellets from $\mathrm{MCO}$ (Figure 2D5) were labeled positively with collagen II in one area of the pellets. Co-cultured pellets of MCI (Figure 2D2) or MCO (Figure 2D4) with MSCs displayed a more intense brown coloration for collagen II than any of the mono-cultured pellets especially prominent at the peripheral rim of the co-cultured pellets. Representative primary antibody control pellets consisting of a 1:3 $\mathrm{MCO} / \mathrm{MSCs}$ ratio were negative and showed no false background staining (Figure $2 \mathrm{E}$ ).

Gene expression profile in mono-cultures and co-cultures of meniscus cells and mesenchymal stromal stem cells The relative mean expressions of aggrecan, collagen I (COL1A2), collagen II (COL2A1), collagen $\times$ (COL10A1), matrix metalloproteinase 13 (MMP-13), Indian Hedgehog $(I H h), S O X 9$, and versican were evaluated at the mRNA level in pellets derived from monocultures of MCI, MCO, and MSCs and from co-cultures of MCI or MCO with MSCs (Figure 3). Mono-cultures of MSCs significantly $(P<0.05)$ expressed the highest (twofold) level of aggrecan mRNA relative to all other pellet cultures (Figure 3A). There was no statistical difference between aggrecan expression in mono-cultures of MCI or MCO and co-cultures of MCI or MCO with MSCs (Figure 3A).

There was no statistically significant difference between the relative mean expression of COL1A2 in cocultures of $\mathrm{MCO}$ or MCI with MSCs (Figure 3B). The expression of COL1A2 was significantly higher (approximately 10 -fold, $P<0.0001)$ in mono-cultures of MSCs and in co-cultures of MCI/MSCs compared with monocultures of MCI but was not different between monocultures of MSCs and co-cultures of MCI/MSCs (Figure $3 \mathrm{~B})$. In contrast, there was no statistical difference between the relative mean expression of COL1A2 in 
A.

Chondrogenic capacity

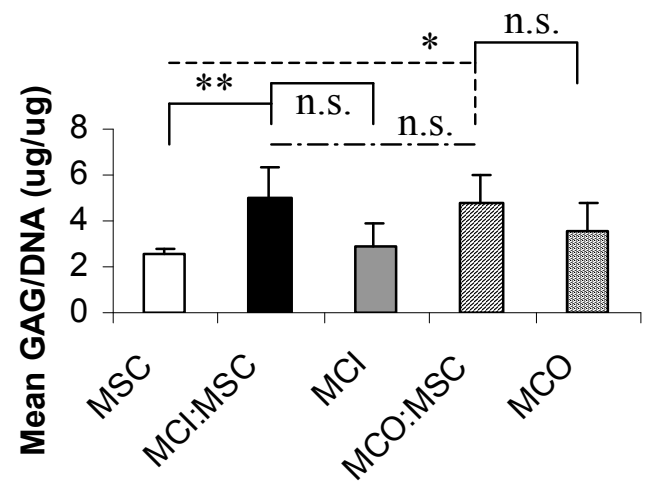

B.

\section{Proliferation index}

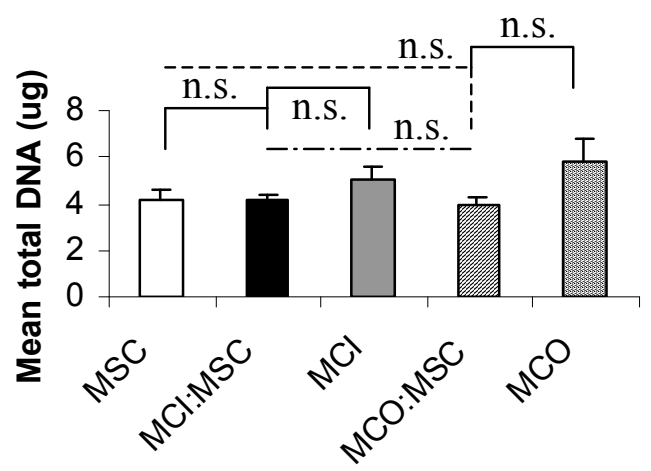

C.

GAG induction

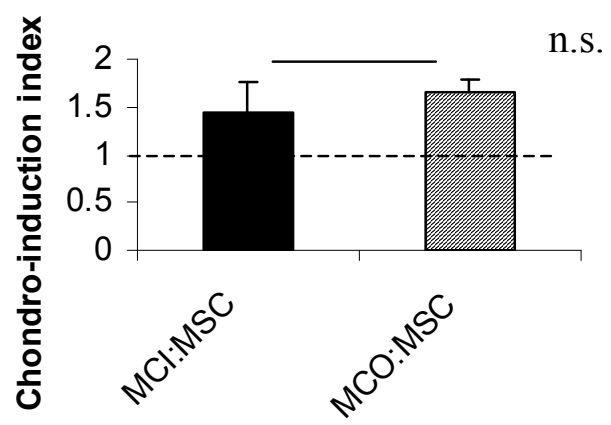

Figure 1 Chondrogenic capacities of outer or inner meniscus cells in co-culture with mesenchymal stromal cells (MSCs) are similar Biochemical analysis was used to evaluate the chondrogenic differentiation capacities (GAG/DNA) and the chondrogenic differentiation indices of the pellets from MSCs, MCI/MSCs, MCl, MCO/MSCs, and MCO after 3 weeks of culture in chondrogenic medium (transforming growth factor-beta 1, dexamethasone, and ascorbate). Chondrogenic induction index was calculated with equations 1 and 2 in the Biochemical analysis subsection of Materials and methods. If the chondro-induction index was greater than 1, an enhancement in chondrogenic matrix formation was considered to have occurred. Data are presented as mean \pm standard error of mean of four donor pairs. One-way analysis of variance with Tukey's multiple comparison post tests: *significance when compared with mono-cultures of meniscus cells - outer meniscus cells (MCO) or inner meniscus cells (MCI) and MSC pellet controls $(P<0.05)$; ** significance when compared with MCO or MCI and MSC pellet controls $(P<0.0001)$. Paired two-tailed Student $t$ statistics: no significance (n.s.) $(P>0.05)$ between chondro-induction indices of co-cultures of MCO or MCl and MSCs. GAG, glycosaminoglycan; MCl, meniscus cells from inner meniscus region; MCO, meniscus cells from the outer meniscus region. 


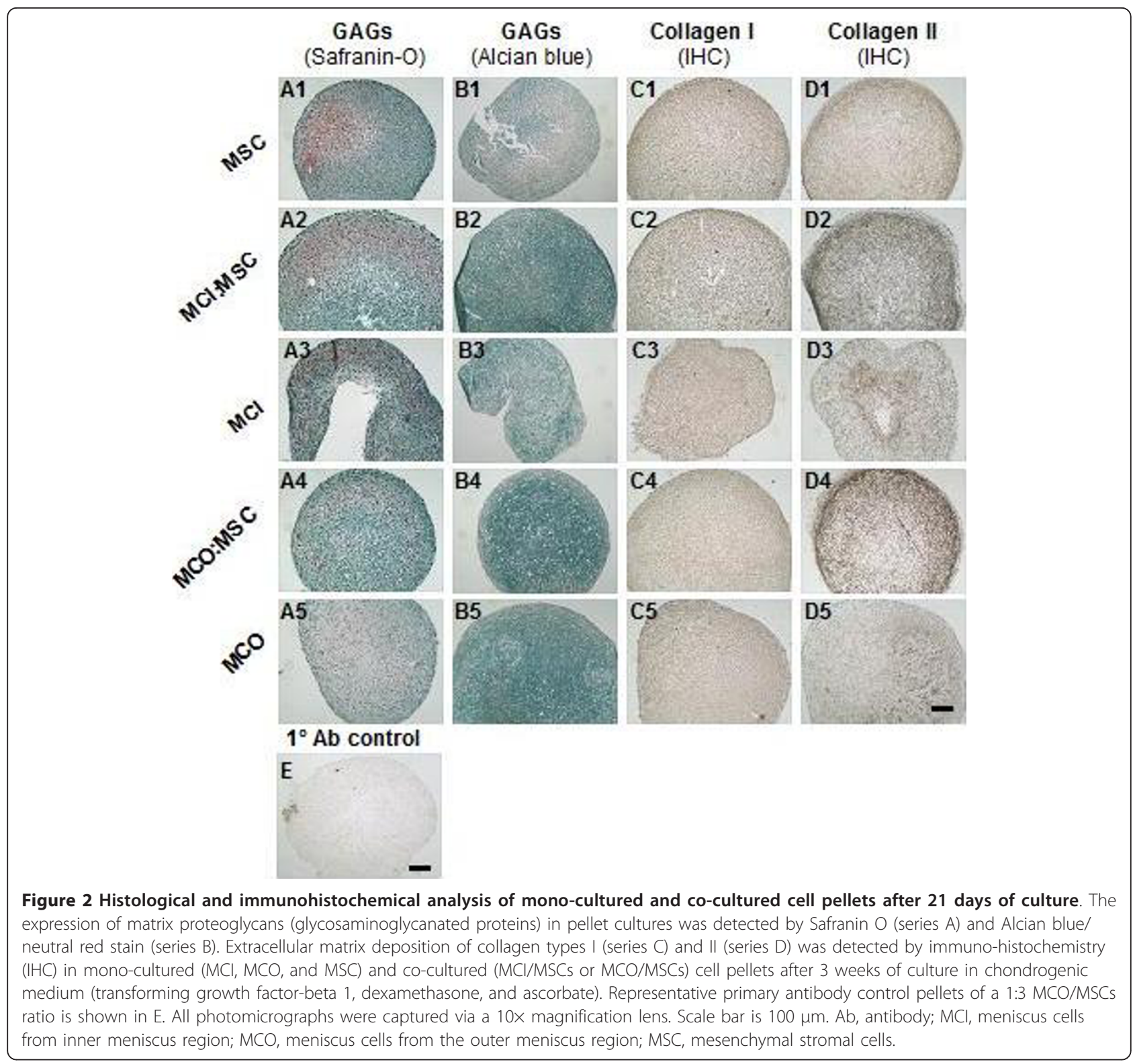

mono-cultures of $\mathrm{MCO}$ and co-cultures of $\mathrm{MCO} / \mathrm{MSCs}$ (Figure 3B).

The mean expression of COL2A1 mRNA was twofold higher in co-cultured pellets of $\mathrm{MCO} / \mathrm{MSCs}$ relative to mono-cultures of MSCs/MCO (Figure 3C). The expression of COL2A1 in co-cultures of $\mathrm{MCI} / \mathrm{MSCs}$ was not significantly different $(P>0.05)$ from its expression in mono-cultures of MSCs. However, COL2A1 expression in co-cultures of MCI/MSCs was ninefold $(P<0.001)$ greater than its expression in mono-cultures of $\mathrm{MCI}$ (Figure 3C).

The gene expressions of hypertrophic genes, COL10A1, MMP-13, and $I H h$, were determined (Figure $3 \mathrm{D}-\mathrm{F})$. The relative mean expression level of COL10A1 was significantly different $(P<0.001)$ and highest in mono-cultured pellets of MSCs relative to other monocultured and co-cultured pellets (Figure 3D), and its expression was least in mono-cultures of MCI or MCO. The addition of MCI or MCO to MSCs in co-cultured pellets resulted in a highly significant suppression of COL10A1 mRNA when compared with its expression in mono-cultures of MSCs (Figure 3D). MCO significantly $(P<0.05)$ suppressed the mRNA expression of COL10A1 by twofold more than its MCI counterpart (Figure 3D). The relative mean expression level of $M M P-13$ was not statistically different between mono-cultures of MSCs and MCI, nor was there any statistical difference between mono-culture MSCs and co-cultures of MSCs 
A.

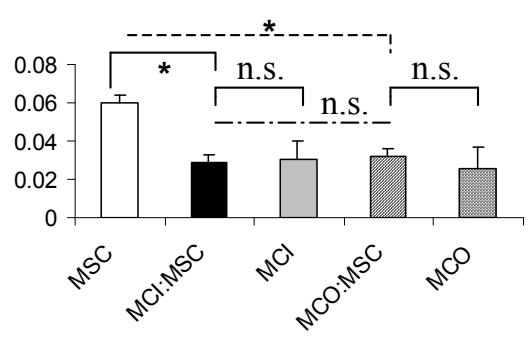

C.

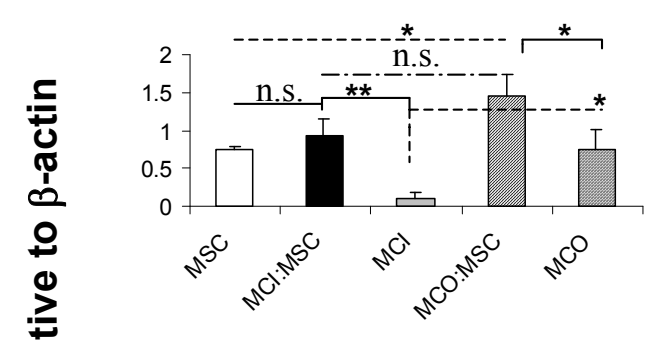

E. MMP-13

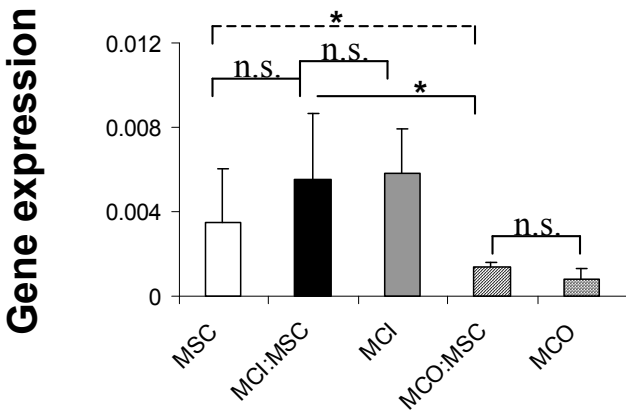

G.

Sox 9

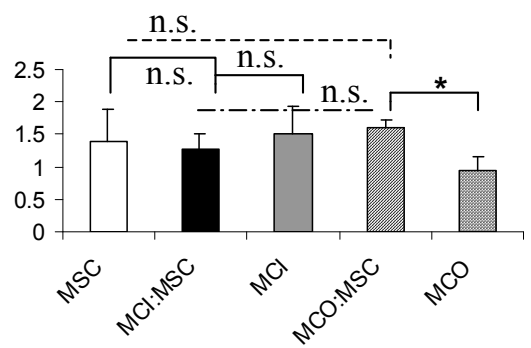

B. Collagen I

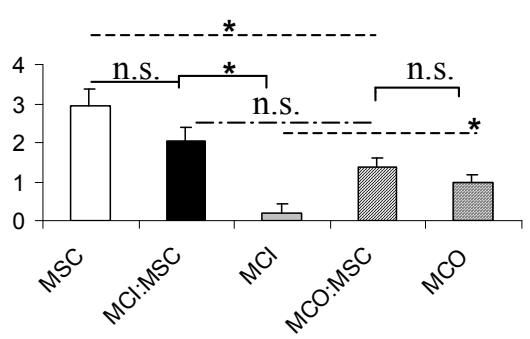

D. Collagen $X$

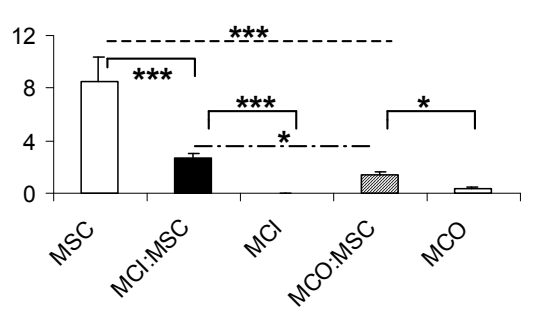

F. Indian Hedgehog

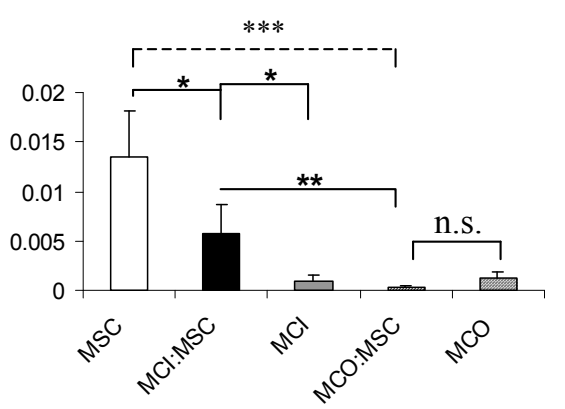

H. Versican

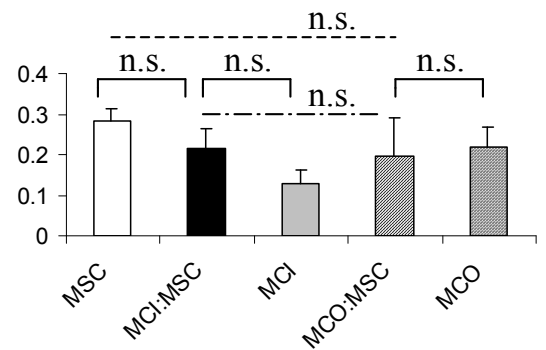

Figure 3 Gene expression analysis of mono-cultured and co-cultured cell pellets after $\mathbf{2 1}$ days of culture. Quantitative mRNA gene expression analysis via SYBR Green detection was used to evaluate the expression of a panel of fibrogenic (Collagen I and Versican) and chondrogenic (Aggrecan, Collagen II and SOX9) marker genes as well as the expression of genes characteristic of hypertrophic differentiation of MSCs (Collagen X, MMP-13 and Indian Hedgehog) in pellets from MSCs, MCI/MSCs, MCl, MCO/MSCs, and MCO after 3 weeks of culture in chondrogenic medium (transforming growth factor-beta 1, dexamethasone, and ascorbate). Each data point represents the mean \pm standard error of the mean of four donor pairs. Oneway analysis of variance with Tukey's multiple comparison post tests: *significance when compared with mono-cultures of meniscus cells - outer meniscus cells (MCO) or inner meniscus cells (MCI) - and MSC pellet controls $(P<0.05)$ or when compared with mono-cultures of MCO versus monocultures of $\mathrm{MCl}$; ** significance when compared with co-cultures of $\mathrm{MCO}$ or $\mathrm{MCl}$ and $\mathrm{MSC}$ pellet controls $(P<0.01)$; ${ }^{* *}$ significance when compared with $\mathrm{MCO}$ or $\mathrm{MCl}$ and $\mathrm{MSC}$ pellet controls $(P<0.0001)$. No significance (n.s.) $(P>0.05)$. All marker gene expression was presented as relative mRNA level normalized to human $\beta$-actin (y-axis); (A) Aggrecan, (B) Collagen I (COL1A2), (C) Collagen II (COL2A1), (D) Collagen $\times$ (COL10A1), (E) MMP-13, (F) Indian Hedgehog $(\mathrm{IHh}),(\mathrm{G})$ Sox9, and $(\mathrm{H})$ Versican MCl, meniscus cells from inner meniscus region; MCO, meniscus cells from the outer meniscus region; MMP-13, matrix metalloproteinase 13; MSC, mesenchymal stromal cell; SOX9, Sry-related HMG box 9. 
and MCI (Figure 3E). However, the mean relative expression of MMP-13 in mono-cultures of MSCs was threefold higher than its expression in co-cultures of MSCs and MCO. The expression of MMP-13 was fourfold higher in $\mathrm{MSC} / \mathrm{MCI}$ co-cultures relative to expression in $\mathrm{MCO} / \mathrm{MSC}$ co-cultures (Figure 3E). The expression of $\mathrm{IHh}$ was highest in mono-cultures of MSCs and lowest in co-cultures of MCO and MSCs (Figure 3F). The expression of $I H h$ in mono-cultures of MSCs was 2.3 -fold higher $(P<0.05)$ than in co-cultures of MSCs and MCI. However, when IHh gene expression in MSC mono-cultures was compared with its expression in MCO/MSC co-cultures, it was 44 -fold higher ( $P$ $<0.0001)$. Additional comparison showed that the expression of $I H h$ in $\mathrm{MCI} / \mathrm{MSCs}$ relative to expression in $\mathrm{MCO} / \mathrm{MSCs}$ was 18 -fold higher $(P<0.001)$ (Figure $3 \mathrm{~F})$.

The expression of Sox9, a transcription factor known to facilitate COL2A1 expression, was not significantly different between most pellet cultures except in monocultures of $\mathrm{MCO}$, where its relative mean expression level was almost twofold lower compared with the other pellets (Figure 3G). There was no statistically significant difference between mono-cultured and co-cultured pellets with regard to mRNA expression of versican (Figure $3 \mathrm{H})$.

\section{Discussion}

Our previous study demonstrated that direct cell-to-cell co-culture of primary human meniscus cells from all regions of the meniscus with bone marrow-derived MSCs resulted in increased matrix formation [39]. However, we did not determine if the cells from the outervascular and inner-avascular regions of the meniscus interacted with MSCs similarly or otherwise. The response of cells of outer and inner menisci to culture conditions and growth factors is different, and the expression of COL2A1 and aggrecan is higher in monolayer cultures of porcine inner meniscus cells than in outer meniscus cells [42]. We showed that, in aggregate cultures of human inner and outer meniscus cells in the presence of TGF- $\beta 1$, hypoxia (5\%) increased the expression of Sox9 in outer meniscus cells but not in inner meniscus cells [44].

In this study, we isolated cells from the inner and outer regions of the meniscus and co-cultured the cells separately with bone marrow-derived MSCs by using the scaffold-free three-dimensional pellet model of tissue formation. Co-culture of primary inner or outer meniscus cells with MSCs resulted in enhanced matrix formation since the calculated interaction indices were greater than 1 . This finding was consistent with the data from our recent work on co-culture of whole meniscus cells with MSCs [35]. Furthermore, our results corroborated the findings of similar studies that involved co-culture of chondrocytes or intervertebral discs with MSCs and that resulted in enhanced matrix synthesis $[32,35]$. The mechanism underlying the enhancement of matrix synthesis was not explored in this study. However, it was interesting to find that the cellularities of the pellets (as judged by the DNA content of our pellets) were not statistically different among experimental and control groups. In a previous study involving co-culture of primary chondrocytes and MSCs, enhanced matrix synthesis was attributed to a synergistic increase in chondrocyte proliferation and induced chondrogenesis of MSCs [35]. However, the lack of difference between the DNA contents of the pellets in this study suggests that the underlying mechanism is most likely independent of changes in cell proliferation. Moreover, our DNA data are consistent with the findings of Furumatsu and colleagues [43], who showed that the proliferation rates of both inner and outer human meniscus cells were the same in the presence of TGF- $\beta 1(10 \mathrm{ng} / \mathrm{mL})$ as used in this study. Other mechanistic possibilities may involve a synergistic cross-talk mediated by soluble factors from both meniscus cells and MSCs [31,52].

Histological and biochemical analyses of the pellets in this study revealed that the cells from the outer and inner regions of the meniscus interacted almost indistinguishably with MSCs. Proteoglycan staining via safranin $\mathrm{O}$ and Alcian blue stains were similar, and the GAG content normalized to DNA content were also similar (Figure 1). This finding was surprising as Furumatsu and colleagues [43] recently reported that human inner meniscus cells have a higher GAG content than outer meniscus cells, even after cultivation in chondrogenic factors. The reason for this is not clear but may be associated with differences in the severity of OA in the specimens used in this study. Furumatsu and colleagues used specimens from medial-affected OA joints (that is, specimens from joints with sufficient articular cartilage of lateral femoral condyle and undegenerated lateral meniscus), whereas this study used both lateral and medial menisci from joints with macroscopically diverse, degenerated articular cartilage of lateral and medial femoral condyles. This possibility is further supported by the findings of Sun and colleagues [53], who demonstrated that altered gene expression profiles exist between $\mathrm{OA}$ and normal menisci.

Collagen I (COL1A2) is the predominant collagen type and ECM molecule in meniscus [5,6]. Co-culture of inner or outer meniscus cells with MSCs resulted in the upregulation of COL1A2 transcription, as we previously reported [39]. Similarly to previous findings, at the protein level, collagen I deposition was qualitatively the same in all pellets. Furthermore, there was no statistical difference between its transcriptional expressions in the 
two co-cultures. Similarly to our previous findings with co-cultures of whole meniscus cells and MSCs [39], the levels of expression of COL1A2 in co-cultures of inner or outer meniscus cells with MSCs appear to be orchestrated by the MSC component since the level of COL1A2 expression in mono-cultures of MSCs was not surpassed. The underlying mechanism for this regulatory role of MSCs is not clear at this point but may be related to trophic activities of MSCs [31,54]. Nonetheless, our data were consistent with our previous findings that COL1A2 expression is higher in human outer meniscus cells than in inner meniscus cells chondrogenic culture [44].

We investigated the gene expression of aggrecan, which is the predominant proteoglycan of the meniscus [55], and versican, another proteoglycan expressed in the meniscus [56], to confirm our histological and biochemical findings. The relative expression levels of aggrecan and versican were not statistically different between co-cultures of inner or outer meniscus cells with MSCs, nor was there any difference between their expression in mono-cultures of inner and outer human meniscus cells (Figure 3A). These findings seem contrary to previous reports that the mRNA expression of aggrecan is higher in inner meniscus cells than in outer meniscus cells. Further contrasts to previous findings were noted in our results on collagen II (COL2A1) expression. Our data demonstrated that the expression of COL2A1 was least in mono-cultures of inner meniscus cells and highest in co-cultures of outer or inner meniscus cells with MSCs relative to mono-cultures of MSCs or outer meniscus cells. However, previous findings by us [44] and Furumatsu and colleagues [43] demonstrated that COL2A1 and Sox9 (a transcription factor known to promote COL2A1) expression in inner meniscus cells was higher relative to their expression in outer meniscus cells, even in the presence of chondrogenic factors. A plausible reason for this disparity between our findings here and those of previous studies is donor-donor variability (age, gender, and so on) or, as alluded to earlier, the association with possible differences in the severity of OA among study specimens [53,57]. Additionally, it is probable that differences in the multi-potential characteristics of outer and inner meniscus cells play a contributing factor. Mauck and colleagues [41] showed that bovine meniscus cells from the inner and outer regions of the meniscus exhibit different multi-lineage differentiation capabilities. Cells from the outer region were more plastic than inner meniscus cells, differentiating along all three mesenchymal lineages (adipogenesis, chondrogenesis, and osteogenesis). Mauck and colleagues also showed that, when outer or inner meniscus cells were treated with chondrogenic factors (as in this study), inner and outer cell populations expressed similar levels of aggrecan. In contrast, in the absence of chondrogenic factors, the expression of aggrecan in inner meniscus is significantly higher than its expression in outer meniscus [42]. Despite the dissimilarities in our aggrecan and COL2A1 data relative to previous reports, it was interesting that the expression of Sox 9 and COL2A1 correlated linearly in monocultures of MSCs and MCO and in co-cultures of $\mathrm{MCO} / \mathrm{MSCs}$ but inversely in mono-cultures of MCI (Figure 3C,E). The expressions of Sox 9 and COL2A1 often are not correlated [57-59], but our findings suggest that, although Sox 9 is necessary for COL $2 A 1$ expression, other factors may facilitate COL $2 A 1$ transcription in inner meniscus. These factors may be particularly active in specimens derived from OA joints and perhaps reflect the similarities of the inner meniscus and articular cartilage $[30,53,57]$. The deposition and distribution of collagen II were notably enhanced in cocultures of inner or outer meniscus cells with MSCs and in mono-cultures of MSCs. This correlated with our previous findings involving whole meniscus cells and MSCs [39].

Further gene expression analysis showed statistically significant differences between the expressions of hypertrophic genes, COL1OA1, IHh, and MMP-13, in co-cultures of MSCs with outer or inner meniscus cells. COL1OA1, IHh, and MMP-13 are predominantly expressed by hypertrophic chondrocytes during endochondral ossification [60]. COL10A1 is also a hypertrophic marker for OA cartilage and OA meniscus $[61,62]$. Expression of both $I H h$ and $M M P-13$ modulates hypertrophic differentiation of chondrocytes during endochondral ossification. IHh is produced by hypertrophic chondrocytes and, in turn, stimulates secretion of parathyroid hormone-related protein (PTHrP), which acts directly on the chondrocytes to slow the pace of hypertrophic chondrocyte differentiation during endochondral ossification [63]. Increased MMP-13 expression and activity have been implicated in extensive reorganization of ECM during endochondral ossification [62]. Our results showed that outer meniscus cells had a greater potency to suppress hypertrophic differentiation of MSCs than inner meniscus cells. This finding was particularly surprising since inner meniscus cells have been shown to display a reduced osteogenic plasticity relative to outer meniscus cells [41]. The reason for this difference is unclear, but it is plausible that outer meniscus cells have a greater capacity to secrete PTHrP than inner meniscus cells. PTHrP was shown to suppress the mRNA expression of COL1OA1 [64]. This aspect of the study merits further investigation.

Co-culture of outer or inner meniscus cells with MSCs exhibit similar capacity to synthesis cartilaginous matrix with increased collagen II and proteoglycan 
content relative to mono-cultures of MSCs, outer or inner meniscus cells. This finding suggests that primary meniscus cells from the outer and reparative region of the meniscus, after supplementation with MSCs, can in principle be used to generate functional grafts or substitutes for the reconstruction of irreparable or degenerate inner meniscus. This possibility is supported by the findings of Kobayashi and colleagues [65], who showed that explants of the outer meniscus integrated well after transplantation to the inner-avascular region of the meniscus. Additionally, our finding regarding the enhanced potency of outer meniscus cells (compared with inner meniscus cells) to suppress hypertrophic differentiation of MSCs makes it an attractive cell source for the reconstruction of the inner meniscus. Furthermore, supplementation of primary meniscus cells with MSCs will mitigate the need to expand meniscus cells for cell-based meniscus tissue engineering purposes since expanded meniscus cells lose their functional matrix-forming phenotype during in vitro expansion.

\section{Conclusions}

Taken together, our results demonstrate that outer or inner meniscus cells interact similarly and synergistically with MSCs to increase matrix formation in the presence of chondrogenic factors. However, outer meniscus cells showed a more potent capacity to suppress the expression of hypertrophic differentiation of MSCs than cells from the inner region of the meniscus. These results suggest that the combination of outer meniscus cells and MSCs can be used in cell-based tissue engineering strategies to reconstruct the inner meniscus.

\section{Abbreviations \\ COL1A2: type II collagen a2 chain; COL2A1: type I collagen a1 chain; COL10A1: type $\times$ collagen a1 chain; ECM: extracellular matrix; EDTA: ethylenediaminetetraacetic acid; FGF-2: basic fibroblast growth factor 2; GAG: glycosaminoglycan; $\mathrm{MCl}$ : meniscus cells from inner meniscus region; MCO: meniscus cells from the outer meniscus region; MMP-13: matrix metalloproteinase 13; MSC: mesenchymal stromal stem cells; OA: osteoarthritis; PTHrP: parathyroid hormone-related peptide; SOX9: Sry-related HMG box 9; TGF- $\beta 1$ : transforming growth factor-beta 1.}

\section{Acknowledgements \\ Financial support was provided in part by the Edmonton Orthopaedic Research Committee of the University of Alberta Hospital Foundation (to $A B A)$ and a new investigator startup fund by the Department of Surgery of the University of Alberta (to ABA). We thank Thomas Churchill and Edward Masson (Department of Surgery, University of Alberta) for histological processing and tissue procurement, respectively, and Jacek Studzinski for histological assistance.}

\section{Authors' contributions}

DJJS helped to perform experiments and data acquisition and shared responsibility for tissue procurement. AM-S helped to perform experiments and data acquisition. NMJ shared responsibility for tissue procurement, data analysis, and manuscript writing. ABA conceived and designed the study, performed experiments and data acquisition and analysis, wrote the manuscript, and supervised the entire study. All authors read and approved the final manuscript.

\section{Competing interests}

The authors declare that they have no competing interests.

Received: 30 March 2012 Revised: 4 June 2012 Accepted: 22 June 2012 Published: 22 June 2012

\section{References}

1. Fithian DC, Kelly MA, Mow VC: Material properties and structure-function relationships in the menisci. Clin Orthop 1990, 252:19-31.

2. Ahmed AM: The load-bearing role of the knee meniscus. In Knee Meniscus: Basic and Clinical Foundations. Edited by: Mow VC, Arnoczky SP, Jackson DW. New York: Raven Press, Ltd; 1992:59-73.

3. Levy IM, Torzilli PA, Fisch ID: The contribution of the menisci to the stability of the knee. In Knee Meniscus: Basic and Clinical Foundations. Edited by: Mow VC, Arnoczky SP, Jackson DW. New York: Raven Press, Ltd; 1992:107-115.

4. McDevitt CA, Miller RR, Spindler KP: The cells and cell matrix interactions of the meniscus. In Knee Meniscus: Basic and Clinical Foundations. Edited by: Mow VC, Arnoczky SP, Jackson DW. New York: Raven Press; 1992:29-36.

5. McDevitt CA, Mukherjee S, Kambic H, Parker R: Emerging concepts of the cell biology of the meniscus. Curr Opin Orthop 2002, 13:345-350.

6. Adams ME, Hukins DWL: The extracellular matrix of the meniscus. In Knee Meniscus: Basic and Clinical Foundations. Edited by: Mow VC, Arnoczky SP, Jackson DW. New York: Raven Press Ltd; 1992:15-28.

7. Melrose J, Smith S, Cake M, Read R, Whitelock J: Comparative spatial and temporal localization of perlecan, aggrecan and type I, II and IV collagen in the ovine meniscus: an ageing study. Histochem Cell Biol 2005, 12:225-235.

8. Tanaka T, Fujii K, Kumagae $Y$ : Comparison of biochemical characteristics of cultured fibrochondrocytes isolated from the inner and outer regions of human meniscus. Knee Surg Sports Traumatol Arthrosc 1999, 7:75-80.

9. Rath $\mathrm{E}$, Richmond JC: The menisci: basic science and advances in treatment. Br J Sports Med 2000, 34:252-257.

10. Arnoczky SP, Warren RF: Microvasculature of the human meniscus. Am $J$ Sports Med 1982, 10:90-95.

11. Arnoczky SP: Gross and vascular anatomy of the meniscus and its role in meniscal healing, regeneration, and remodelling. In Knee Meniscus: Basic and Clinical Foundations. Edited by: Van C Mow, Steven P Arnoczky, Douglas W Jackson. New Nork: Raven Press Ltd; 1992:1-14.

12. Arnoczky SP, Warren RF: The microvasculature of the meniscus and its response to injury. An experimental study in the dog. Am J Sports Med 1983, 11:131-141.

13. Aagaard $H$, Verdonk R: Function of the normal meniscus and consequences of meniscal resection. Scand J Med Sci Sports 1999, 9:134-140

14. Aagaard $\mathrm{H}$, Jorgensen $U$, Bojsen-Moller F: Reduced degenerative articular cartilage changes after meniscal allograft transplantation in sheep. Knee Surg Sports Traumatol Arthrosc 1999, 7:184-191.

15. Fairbank T: Knee joint changes after menisectomy. J Bone Joint Surg 1948, 30B:664-670.

16. McDermott ID, Amis AA: The consequences of meniscectomy. J Bone Joint Surg Br 2006, 88:1549-1556.

17. Angele P, Johnstone B, Kujat R, Zellner J, Nerlich M, Goldberg V, Yoo J: Stem cell based tissue engineering for meniscus repair. J Biomed Mater Res A 2008, 85:445-455.

18. Buma $P$, Ramrattan NN, van Tienen $T G$, Veth RP: Tissue engineering of the meniscus. Biomaterials 2004, 25:1523-1532.

19. Nakata K, Shino K, Hamada M, Mae T, Miyama T, Shinjo H, Horibe S, Tada K, Ochi T, Yoshikawa H: Human meniscus cell: characterization of the primary culture and use for tissue engineering. Clin Orthop Relat Res 2001, 391(Suppl):S208-218.

20. Chiari C, Koller U, Dorotka R, Eder C, Plasenzotti R, Lang S, Ambrosio L, Tognana $E$, Kon E, Salter D, Nehrer S: A tissue engineering approach to meniscus regeneration in a sheep model. Osteoarthritis Cartilage 2006, 14:1056-1065.

21. Marsano A, Millward-Sadler SJ, Salter DM, Adesida A, Hardingham T, Tognana E, Kon E, Chiari-Grisar C, Nehrer S, Jakob M, Martin I: Differential cartilaginous tissue formation by human synovial membrane, fat pad, meniscus cells and articular chondrocytes. Osteoarthritis Cartilage 2007, 15:48-58. 
22. Marsano A, Wendt D, Raiteri R, Gottardi R, Stolz M, Wirz D, Daniels AU, Salter D, Jakob M, Quinn TM, Martin I: Use of hydrodynamic forces to engineer cartilaginous tissues resembling the non-uniform structure and function of meniscus. Biomaterials 2006, 27:5927-5934

23. Baker BM, Nathan AS, Huffman GR, Mauck RL: Tissue engineering with meniscus cells derived from surgical debris. Osteoarthritis Cartilage 2009, 17:336-345.

24. Gunja NJ, Athanasiou KA: Effects of co-cultures of meniscus cells and articular chondrocytes on PLLA scaffolds. Biotechnol Bioeng 2009, 103:808-816

25. Pabbruwe MB, Kafienah W, Tarlton JF, Mistry S, Fox DJ, Hollander AP: Repair of meniscal cartilage white zone tears using a stem cell/collagenscaffold implant. Biomaterials 2010, 31:2583-2591.

26. Martinek V, Ueblacker P, Braun K, Nitschke S, Mannhardt R, Specht K, Gansbacher B, Imhoff AB: Second generation of meniscus transplantation: in vivo study with tissue engineered meniscus replacement. Arch Orthop Trauma Surg 2006, 126:228-234.

27. Hoben GM, Athanasiou KA: Meniscal repair with fibrocartilage engineering. Sports Med Arthrosc 2006, 14:129-137.

28. Hoben GM, Athanasiou KA: Creating a spectrum of fibrocartilages through different cell sources and biochemical stimuli. Biotechnol Bioeng 2008, 100:587-598

29. Pittenger MF, Mackay AM, Beck SC, Jaiswal RK, Douglas R, Mosca JD, Moorman MA, Simonetti DW, Craig S, Marshak DR: Multilineage potential of adult human mesenchymal stem cells. Science 1999, 284:143-147.

30. Makris EA, Hadidi P, Athanasiou KA: The knee meniscus: structurefunction, pathophysiology, current repair techniques, and prospects for regeneration. Biomaterials 2011, 32:7411-7431.

31. Caplan Al, Dennis JE: Mesenchymal stem cells as trophic mediators. J Cell Biochem 2006, 98:1076-1084.

32. Yamamoto $Y$, Mochida J, Sakai D, Nakai T, Nishimura K, Kawada H, Hotta T: Upregulation of the viability of nucleus pulposus cells by bone marrowderived stromal cells: significance of direct cell-to-cell contact in coculture system. Spine 2004, 29:1508-1514

33. Vadala G, Studer RK, Sowa G, Spiezia F, lucu C, Denaro V, Gilbertson LG, Kang JD: Coculture of bone marrow mesenchymal stem cells and nucleus pulposus cells modulate gene expression profile without cell fusion. Spine 2008, 33:870-876.

34. Richardson SM, Walker RV, Parker S, Rhodes NP, Hunt JA, Freemont AJ, Hoyland JA: Intervertebral disc cell-mediated mesenchymal stem cell differentiation. Stem Cells 2006, 24:707-716.

35. Acharya C, Adesida A, Zajac P, Mumme M, Riesle J, Martin I, Barbero A: Enhanced chondrocyte proliferation and mesenchymal stromal cells chondrogenesis in coculture pellets mediate improved cartilage formation. J Cell Physiol 2012, 227:88-97.

36. Tsuchiya K, Chen GP, Ushida T, Matsuno T, Tateishi T: The effect of coculture of chondrocytes with mesenchymal stem cells on their cartilaginous phenotype. Materials Science and Engineering C 2004, 24:391-396.

37. Hendriks J, Riesle J, van Blitterswijk CA: Co-culture in cartilage tissue engineering. J Tissue Eng Regen Med 2007, 1:170-178.

38. Hendriks JA, Miclea RL, Schotel R, de Bruijn E, Moroni L, Karperien M, Riesle J, van Blitterswijk CA: Primary chondrocytes enhance cartilage tissue formation upon co-culture with a range of cell types. Soft Matter 2010, 6:5080-5088.

39. Matthies N, Mulet-Sierra A, Jomha NM, Adesida A: Matrix formation is enhanced in co-cultures of human meniscus cells with bone marrow stromal cells. J Tissue Eng Regen Med 2012.

40. Cui X, Hasegawa A, Lotz M, D'Lima D: Structured three-dimensional coculture of mesenchymal stem cells with meniscus cells promotes meniscal phenotype without hypertrophy. Biotechnol Bioeng 2012.

41. Mauck RL, Martinez-Diaz GJ, Yuan X, Tuan RS: Regional multilineage differentiation potential of meniscal fibrochondrocytes: implications for meniscus repair. Anat Rec (Hoboken) 2007, 290:48-58.

42. Upton ML, Chen J, Setton LA: Region-specific constitutive gene expression in the adult porcine meniscus. J Orthop Res 2006, 24:1562-1570.

43. Furumatsu T, Kanazawa T, Yokoyama Y, Abe N, Ozaki T: Inner meniscus cells maintain higher chondrogenic phenotype compared with outer meniscus cells. Connect Tissue Res 2011, 52:459-465.
44. Adesida AB, Grady LM, Khan WS, Millward-Sadler SJ, Salter DM, Hardingham TE: Human meniscus cells express hypoxia inducible factor1alpha and increased SOX9 in response to low oxygen tension in cell aggregate culture. Arthritis Res Ther 2007, 9:R69.

45. Mastrogiacomo M, Cancedda R, Quarto R: Effect of different growth factors on the chondrogenic potential of human bone marrow stromal cells. Osteoarthritis Cartilage 2001, 9:S36-40.

46. Adesida A, Matthies N, Sierra A, Studzinski J, Churchill T, Masson E, Jomha N: Human meniscus cells' matrix is enhanced after coculture with bone marrow stromal cells and further by low oxygen tension. Paper presented at: 57th Annual Meeting of the Orthopaedic Research Society; 13-16 Jan. 2011; Long Beach, CA, USA.

47. Farndale RW, Buttle DJ, Barrett AJ: Improved quantitation and discrimination of sulphated glycosaminoglycans by use of dimethylmethylene blue. Biochim Biophys Acta 1986, 883:173-177.

48. Murdoch AD, Grady LM, Ablett MP, Katopodi T, Meadows RS, Hardingham TE: Chondrogenic differentiation of human bone marrow stem cells in transwell cultures: generation of scaffold-free cartilage. Stem Cells 2007, 25:2786-2796.

49. Adesida AB, Grady LM, Khan WS, Hardingham TE: The matrix-forming phenotype of cultured human meniscus cells is enhanced after culture with fibroblast growth factor 2 and is further stimulated by hypoxia. Arthritis Res Ther 2006, 8:R61.

50. Livak KJ, Schmittgen TD: Analysis of relative gene expression data using real-time quantitative PCR and the 2-[delta][delta]CT method. Methods 2001, 25:402-408.

51. Jakob M, Demarteau O, Schafer D, Stumm M, Heberer M, Martin I: Enzymatic digestion of adult human articular cartilage yields a small fraction of the total available cells. Connect Tissue Res 2003, 44:173-180.

52. Ahmed N, Dreier R, Gopferich A, Grifka J, Grassel S: Soluble signalling factors derived from differentiated cartilage tissue affect chondrogenic differentiation of rat adult marrow stromal cells. Cell Physiol Biochem 2007, 20:665-678.

53. Sun Y, Mauerhan DR, Honeycutt PR, Kneisl JS, Norton JH, Hanley EN Jr, Gruber HE: Analysis of meniscal degeneration and meniscal gene expression. BMC Musculoskelet Disord 2010, 11:19.

54. Wu L, Leijten JC, Georgi N, Post JN, van Blitterswijk C, Karperien M: Trophic effects of mesenchymal stem cells increase chondrocyte proliferation and matrix formation. Tissue Eng Part A 2011, 17:1425-1436.

55. Djurasovic M, Aldridge JW, Grumbles R, Rosenwasser MP, Howell D, Ratcliffe A: Knee joint immobilization decreases aggrecan gene expression in the meniscus. Am J Sports Med 1998, 26:460-466.

56. Hellio LGM, Reno C, Hart DA: Gene expression in menisci from the knees of skeletally immature and mature female rabbits. J Orthop Res 1999, 17:738-744.

57. Brew CJ, Clegg PD, Boot-Handford RP, Andrew JG, Hardingham T: Gene expression in human chondrocytes in late osteoarthritis is changed in both fibrillated and intact cartilage without evidence of generalised chondrocyte hypertrophy. Ann Rheum Dis 2010, 69:234-240.

58. Aigner T, Gebhard PM, Schmid E, Bau B, Harley V, Poschl E: SOX9 expression does not correlate with type II collagen expression in adult articular chondrocytes. Matrix Biol 2003, 22:363-372.

59. Gebhard PM, Gehrsitz A, Bau B, Soder S, Eger W, Aigner T: Quantification of expression levels of cellular differentiation markers does not support a general shift in the cellular phenotype of osteoarthritic chondrocytes. $J$ Orthop Res 2003, 21:96-101.

60. Marriott A, Ayad S, Grant ME: The synthesis of type $\times$ collagen by bovine and human growth-plate chondrocytes. J Cell Sci 1991, 99:641-649.

61. Hellio Le Graverand MP, Sciore P, Eggerer J, Rattner JP, Vignon E, Barclay L, Hart DA, Rattner JB: Formation and phenotype of cell clusters in osteoarthritic meniscus. Arthritis Rheum 2001, 44:1808-1818.

62. Alvarez J, Balbin M, Santos F, Fernandez M, Ferrando S, Lopez JM: Different bone growth rates are associated with changes in the expression pattern of types II and $\times$ collagens and collagenase 3 in proximal growth plates of the rat tibia. J Bone Miner Res 2000, 15:82-94.

63. Kronenberg HM, Lee K, Lanske B, Segre GV: Parathyroid hormone-related protein and Indian hedgehog control the pace of cartilage differentiation. J Endocrinol 1997, 154(Suppl):S39-45.

64. Kafienah W, Mistry S, Dickinson SC, Sims TJ, Learmonth I, Hollander AP: Three-dimensional cartilage tissue engineering using adult stem cells from osteoarthritis patients. Arthritis Rheum 2007, 56:177-187. 
65. Kobayashi K, Fujimoto E, Deie M, Sumen Y, Ikuta Y, Ochi M: Regional differences in the healing potential of the meniscus-an organ culture model to eliminate the influence of microvasculature and the synovium. Knee 2004, 11:271-278.

doi:10.1186/ar3889

Cite this article as: Saliken et al:: Decreased hypertrophic differentiation accompanies enhanced matrix formation in co-cultures of outer

meniscus cells with bone marrow mesenchymal stromal cells. Arthritis

Research \& Therapy 2012 14:R153.

Submit your next manuscript to BioMed Central and take full advantage of:

- Convenient online submission

- Thorough peer review

- No space constraints or color figure charges

- Immediate publication on acceptance

- Inclusion in PubMed, CAS, Scopus and Google Scholar

- Research which is freely available for redistribution

Submit your manuscript at www.biomedcentral.com/submit
() Biomed Central 